\title{
Percutaneous Implantation of Endoprostheses in the Carotid Arteries
}

\author{
José Ribamar Costa Jr., Manuel N. Cano, Dinaldo C. Oliveira, Antonio M. Kambara, \\ Adriana C. Moreira, Rogério Queiroz, Silvia Cano, Amanda G.M.R. Sousa, \\ J. Eduardo M.R. Sousa
}

São Paulo, SP - Brazil

\begin{abstract}
Objective - To assess the in-hospital evolution of patients undergoing percutaneous stent placement in the carotid arteries.

Methods - From August 1996 to April 2001, we studied 86 patients with carotid arterial obliterative lesions $>70 \%$ who were treated with percutaneous stent placement in the carotid arteries. We assessed the rate of success of the implantation and of the procedure, the types of stents used, mortality rate, and neurological complications.
\end{abstract}

Results - Successful implantation was obtained in $98.9 \%$ of the cases, and the procedure was successful in $91.8 \%$. The Wallstent was the most frequently used stent (73 patients - 77\%). Cerebral strokes occurred as follows: $3(3.2 \%)$ transient ischemic attacks, 1 (1.1\%) minor stroke, and $3(3.1 \%)$ major strokes. One (1.1\%) patient died during hospitalization.

Conclusion - The high rate of success of stent implantation (98.9\%) in addition to the low rate of cerebral stroke/death (4.2\%) showed the efficiency and safety of percutaneous stent placement in carotid arteries.

Keywords: placement, stent, carotid arteries

Instituto Dante Pazzanese de Cardiologia, Hospital do Coração and Associação do Sanatório Sírio

Mailing address: José Ribamar Costa Júnior - Rua Botucatu, 221/12 - 04023-060

- São Paulo, SP, Brazil - E-mail: rmvcosta@uol.com.br

English version by Stela Maris C. e Gandour
Cerebral stroke is currently one of the most prevalent diseases. In the United States of America, 800 thousand new cases of cerebral stroke are estimated to occur every year, of which, one third result from atherosclerotic disease with significant carotid artery stenosis ${ }^{1,2}$. Cerebral stroke causes some degree of disability in daily activities in approximately 2 million patients, causing an increase in the number of economically unproductive citizens, which results in a heavy burden on the state ${ }^{3,4}$.

In Brazil, this disease is extremely common. It was computed at first among the afflictions of cerebral origin (cranial traumas excluded), and then, among the general causes of death in the population ${ }^{5}$.

In the 1950s, Eascott, DeBakey, and Cooley were the pioneers in surgical carotid endarterectomy, which, in its initial phase, had some discouraging results. However, with improvement in the surgical technique and in preand postoperative care, the results became more favorable, leading surgical endarterectomy to play a relevant role in the treatment of carotid atherosclerotic disease from the 1970 s on $^{2,6}$. It is estimated that 200 thousand surgical carotid endarterectomies were performed in the USA in $2001^{7}$.

At the end of the 1970s, Mathias et al ${ }^{8,9}$ introduced carotid balloon catheter angioplasty as a therapeutical alternative to surgery.

In the 1990s, with the endoprostheses, the carotid percutaneous treatment became more consolidated, and the short, medium-, and long-term results became extremely encouraging. It is estimated that 3 thousand carotid percutaneous interventions were performed in the USA in $2001^{7,10}$.

We studied the in-hospital evolution of patients undergoing carotid endoprosthesis implantation to assess the rate of success of the implantation and of the procedure, the types of endoprostheses used, the mortality rate, and the possible neurological complications, according to the criteria of the National Institutes of Health ${ }^{11}$. 


\section{Methods}

From August 1996 to April 2001, 86 patients most of whom were males $(51.2 \%)$, with a mean age of 64.3 years $( \pm 22$ years), underwent percutaneous implantation of carotid endoprosthesis. These patients were referred for treatment because they had previous neurological symptoms (amaurosis, presyncope, syncope, and others), or significant atherosclerotic disease in other areas (coronary arteries, lower limbs, renal arteries, and others), or a significant carotid stenosis diagnosed on a noninvasive evaluation (Doppler ultrasound, computerized tomography, nuclear magnetic resonance, and others).

The inclusion criteria were as follows: asymptomatic patients with stenotic lesion $\mathrm{m} 70 \%$, according to quantitative coronary angiography (QCA); patients with a previous history of transient ischemic attack in the last year characterized by episodes of dizziness, syncope, paresis, and temporary paresthesia or amaurosis reported in the side of the angiographic lesion and stenosis $\mathrm{m} 60 \%$; patients with a history of contralateral ischemic cerebral stroke with stenotic lesion $\mathrm{m} 60 \%$ and patent cerebral arteries.

The exclusion criteria were as follows: patients with marked tortuosity at the origin of the supraaortic branches or aorto-iliac obstruction, not allowing the passage of catheters; patients with stenotic lesions, but with mobile thrombi inside; existence of diffuse stenotic lesions in the intracranial portion of the internal carotid artery or in the cerebral arteries; existence of cerebral aneurysms or intracranial arteriovenous malformations; recent history of digestive, pulmonary, or tumor hemorrhages, which contraindicate therapy with antiplatelet agents.

The following patients were considered as high-risk patients for the procedure: those older than 70 years; those with concomitant coronary artery disease; those with significant neurological antecedents (history of convulsion, stroke); those with contralateral carotid occlusion; those undergoing previous surgical carotid endarterectomy and evolving to restenosis; those with cervical neoplasia operated upon or undergoing radiation therapy, or both (characterizing the so-called "hostile neck").

Successful implantation was defined as a residual lesion $<30 \%$ on quantitative digital angiography and absence of important dissections or thrombi, while success of the procedure was characterized by successful implantation in the absence of transient ischemic attack, and of minor and major ischemic stroke according to the definition of the $\mathrm{Na}-$ tional Institutes of Health.

Transient ischemic attack was defined as any neurological deficit reverted in the first 24 hours after the procedure with no residual neurological damage.

Minor ischemic cerebral stroke was defined as a new neurological event resulting in a mild reduction in neurological functions (speech, motor or sensorial function, or both) with complete reversion in the first 7 days after the procedure or reaching up to 4 points in the cerebral stroke scale of the National Institutes of Health. A new neurologi- cal deficit persisting longer than 7 days or reaching 4 or more points in the cerebral stroke scale of the National Institutes of Health was classified as major ischemic cerebral stroke.

The patients were premedicated ( 24 hours) with ticlopidine $(500 \mathrm{mg})$ and acetylsalicylic acid $(200 \mathrm{mg})$, and, after endoprosthesis implantation, they continued to take this association of antiplatelet agents for 30 days, when ticlopidine was suspended and acetylsalicylic acid was maintained indefinitely.

Prior to hospital discharge, all patients were assessed by at least 2 neurologists from the Hospital do Coração and Instituto Dante Pazzanese.

The hemodynamics laboratory was equipped with a chest X-ray device with a 3,000-milliampere generator, 50 to 150 kilovolt peak, high-definition image intensifier $(1,024$ line monitor), and a digital converter for electronic image processing. The images were documented in the digital system with a laser compact disc (CD) or in the analog system in a cinephotographic $35-\mathrm{mm}$ film.

The patient's blood pressure (invasive), oxygen saturation (pulse oximeter), and heart rate (electrocardiogram) were continuously monitored.

After antisepsis, local anesthesia was performed with subcutaneous injection of $20 \mathrm{~mL}$ of a $\%$ lidocaine solution in the right and left inguinal regions. Then, using Seldinger's technique, the right femoral artery and then the left femoral artery were punctured and maintained with 8 and 6 French (F) introducers with valves, respectively. A temporary electrode of a cardiac endocavitary pacemaker was placed in the right ventricle, to which a temporary VVI-mode pacemaker generator with a heart rate of $50 \mathrm{bpm}$ was connected.

The primitive carotid artery was catheterized via the punctured common femoral artery and an $8 / 9 \mathrm{~F}$ guide catheter or a $7 \mathrm{~F}$ long introducer with valves was placed. With injection of a low-osmolarity iodinated contrast agent, a carotid angiography in 2 views (right and left anterior oblique) was obtained. The following parameters were measured with quantitative angiography (SMS): the reference diameter of the vessel, the extension of the lesion, and the minimum luminal diameter prior to the procedure.

Anticoagulation was performed with the intravenous injection of 10,000 units of unfractioned heparin immediately before the use of the 0.014 " guidewire.

After the 0.014" guidewire was passed through the lesion, the balloon catheter $(4 \times 20 \mathrm{~mm})$ was positioned for predilation, which was performed with the aid of a manometer and lasted 10 seconds at the most. Then a new carotid angiography was performed to confirm the absence of complications in the vessel.

Then, the balloon catheter was withdrawn and the guidewire was maintained. The endoprosthesis was then positioned and deployed. In the cases in which "waisting" of the endoprosthesis persisted (residual lesion $>30 \%$ ), a new dilation was performed with a low-profile ( 3.5 to $4 \mathrm{~F}$ ) balloon catheter of 5 or $6 \times 20 \mathrm{~mm}$. 
Control carotid angiography and a shoot of the cerebral circulation were performed. In the absence of thrombi or dissections and confirmation of residual lesion $<30 \%$, the procedure was finished.

The patients were referred to the semi-intensive care unit with cardiac monitoring and maintained on intravenous hydration with saline solution at a velocity of 50 to $70 \mathrm{~mL} / \mathrm{h}$ for 8 to 12 hours. The patients were allowed to eat 4 hours after their arrival at the unit. The introducers and the cardiac pacemaker electrode were removed 4 to 6 hours after the end of the procedure. Hemostasia was performed with local manual compression for approximately 20 minutes, which was complemented with a compressive dressing and immobilization of the lower limb for approximately 8 hours. In case of an uneventful evolution, the patients were transferred to a room after 24 hours, being discharged from the hospital on the following day.

\section{Results}

Ninety-four carotid lesions in 86 patients were treated. Implantation was successful in $98.9 \%$ of the cases, and the procedure was successful in $91.8 \%$ of the cases.

Prior to the procedure, the most common symptom was transient ischemic attack present in $72.9 \%$ of the patients, followed by transitory amaurosis in $10.8 \%$ (tab. I).

Most of the 94 endoprostheses implanted were of the metallic self-expanding type, the Wallstent, used 73 (77.6\%) times. In order of frequency, the other endoprostheses used were as follows: the Smart (self-expanding), the Palmaz (expandable balloon), the Symphony (self-expanding), the Memotherm (self-expanding), and the Herculink (expandable balloon)(fig. 1).

The 7 cases of in-hospital neurological complications were as follows: $3(3.2 \%)$ transient ischemic attacks, 1 (1.1\%) minor ischemic cerebral stroke, and 3 (3.2\%) major ischemic cerebral strokes. These complications occurred when the patients were still in the hemodynamic laboratory and may have been related to microembolism. One patient died at the hospital (14 $4^{\text {th }}$ day).

The combined rate of minor and major ischemic cerebral strokes was $4.2 \%$ (tab. II).

When analyzing the presence of neurological complications according to the presence of symptoms prior to the procedure, we observed that the asymptomatic patients nei-

\begin{tabular}{|lc|}
\hline \multicolumn{2}{|c|}{ Table I - Clinical presentation of symptomatic patients } \\
\hline Symptomatology & $\mathrm{N}^{\circ}$ of patients \\
\hline Transient ischemic attack & $54(72.9 \%)$ \\
Transient amaurosis & $8(10.8 \%)$ \\
Hemifacial paresthesia & $3 \begin{array}{r}(4 \%) \\
\text { Blindness }\end{array}$ \\
Convulsion & $2.7 \%)$ \\
Unspecific (dizziness, vertigo, cognitive & $5(6.7 \%)$ \\
disorders, etc.) & \\
\hline Total & 74 \\
\hline
\end{tabular}

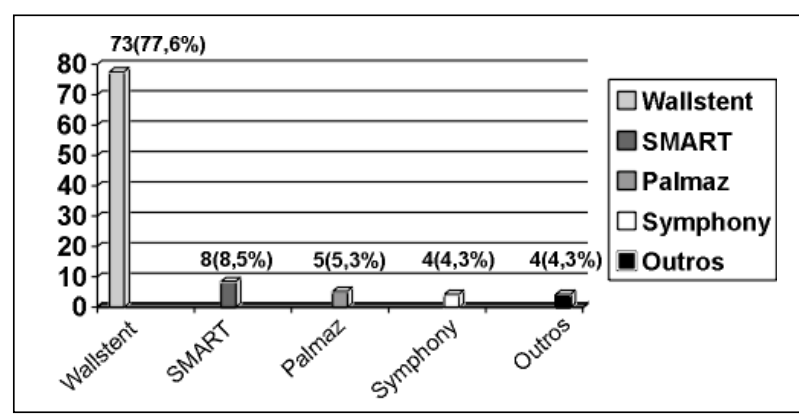

Fig. 1-Types of stents used.

ther had any type of cerebral stroke nor died, while the symptomatic patients had a mortality rate of $1.1 \%$ and an incidence of major ischemic cerebral stroke of $3.2 \%$ (fig. 2).

Pictures 1,2, and 3 depict the procedure of percutaneous implantation of carotid endoprosthesis in a patient in our series.

Only 1 patient had a complication at the site of access (right and left inguinal regions); it was a hematoma of $6 \mathrm{~cm}$ in diameter in the right inguinal region, which resolved spontaneously.

Three patients evolved with total atrioventricular block, the cardiac rhythm being dictated by the temporary pacemaker with recovery of sinus rhythm in the first 24 hours in all cases.

\section{Discussion}

It is believed that an asymptomatic patient with a carotid obstruction $\mathrm{m} 80 \%$ has a $6 \%$ annual risk of having an ischemic cerebral stroke, while a symptomatic patient has a $10 \%$ risk in the first year and a $40 \%$ risk by the end of 5 years ${ }^{12}$.

Surgical carotid endarterectomy should have a rate of cerebral stroke/death $<6 \%$ in symptomatic patients and $3 \%$ in asymptomatic patients ${ }^{13}$.

The rate of ischemic cerebral stroke after surgical carotid endarterectomy has ranged from $1.5 \%$ to $9 \%$, depending on the case series analyzed ${ }^{14,15}$. In the European carotid surgery trial(ECST), the rate of ischemic cerebral stroke/death with this type of surgery was $7.5 \%{ }^{15}$. The North-American Symptomatic Carotid Endarterectomy Trial (NASCET),

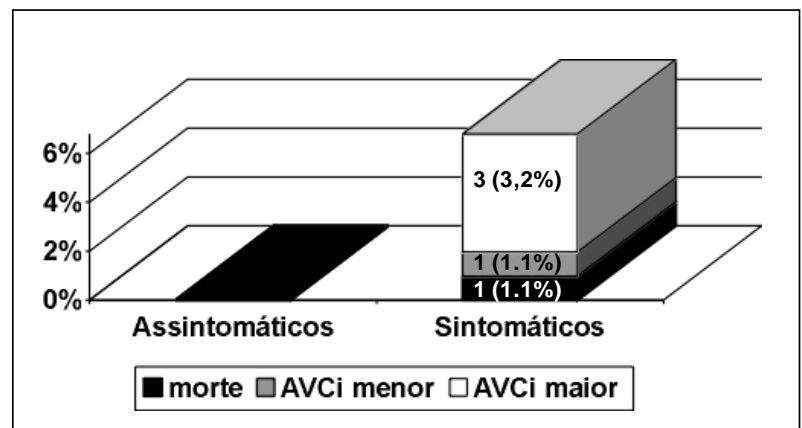

Fig. 2-Complications related to the procedure in symptomatic versus asymptomatic patients. 


\begin{tabular}{|c|c|c|c|}
\hline \multicolumn{4}{|c|}{ Table II - In-hospital complications related to the procedure } \\
\hline Number & & $\begin{array}{c}\% \text { based on } \\
\text { vessels treated (94) }\end{array}$ & $\begin{array}{c}\% \text { based on } \\
\text { patients treated }(86)\end{array}$ \\
\hline TIA & 3 & $3.2 \%$ & $3.5 \%$ \\
\hline Minor ICS & 1 & $1.1 \%$ & $1.2 \%$ \\
\hline Major ICS & 3 & $3.2 \%$ & $3.5 \%$ \\
\hline Deaths resulting from neurological complications & 1 & $1.1 \%$ & $1.2 \%$ \\
\hline Deaths not resulting from neurological complications & 0 & 0 & 0 \\
\hline Total of ICS and deaths related to the procedure & & $5.3 \%$ & $5.8 \%$ \\
\hline
\end{tabular}

which randomized symptomatic patients with 50 to $69 \%$ carotid stenosis for clinical treatment or surgical carotid endarterectomy, revealed a rate of ischemic cerebral stroke/death of $5.8 \%$ in the surgical group ${ }^{16}$. On the other hand, the Asymptomatic Carotid Atherosclerosis Study Group (ACAS) reported a $2.3 \%$ rate of ischemic cerebral stroke/ death related to surgery ${ }^{17}$.

The Carotid and Vertebral Artery Transluminal Angioplasty Study (CAVATAS) randomized 504 patients, 253 for surgical carotid endarterectomy and 251 for percutaneous carotid intervention. The rate of cerebral stroke/death at 30 days was $6.4 \%$ for surgical carotid endarterectomy and 5.9\% for percutaneous carotid intervention. After a 3-year clinical follow-up, the authors obtained equivalence of treatments ${ }^{18}$.

Carotid angioplasty with implantation of endoprostheses is a promising alternative technique to the classic surgical carotid endarterectomy. The study by Whole et al ${ }^{19}$, who analyzed 2,569 patients undergoing carotid endoprosthesis implantation, reported a 30 -day mortality of $1.2 \%$, a combined rate of cerebral stroke/death of $4.3 \%$, and an incidence of restenosis at 180 days of $4.8 \%$.

The use of cerebral protection in percutaneous carotid

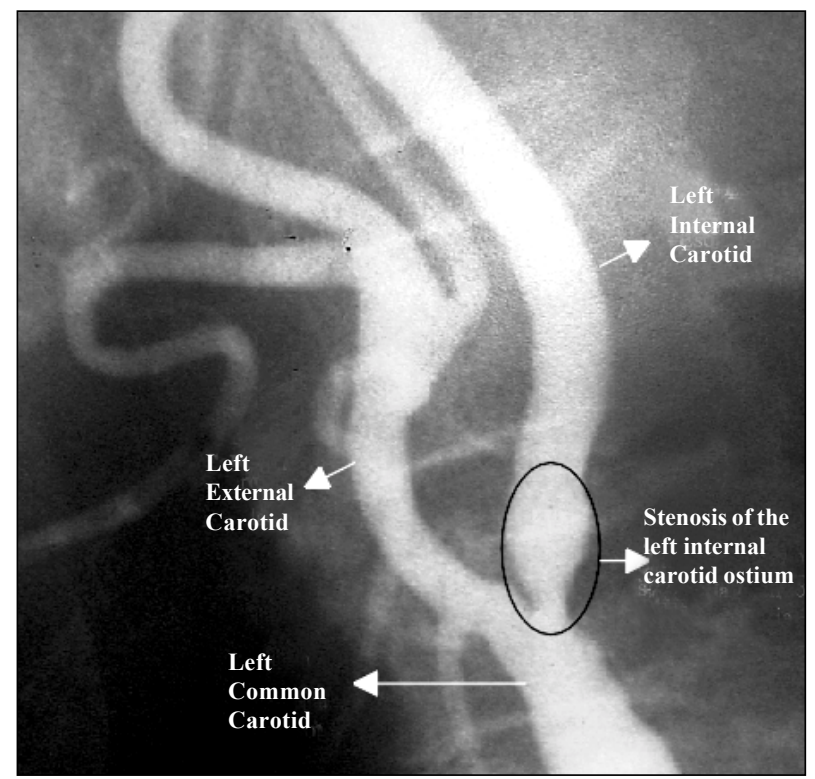

Picture 1 - On quantitative angiography, an $80 \%$ lesion can be seen obstructing the left internal carotid artery ostium (ICA). intervention aiming at reducing the microembolic phenomena has been proposed by some groups. Currently, several systems provide cerebral protection.

In 1990, Theron et al ${ }^{20}$ were the pioneers in the use of cerebral protection with the introduction of a system of distal carotid occlusion with a balloon mounted on a tri-coaxial catheter, therefore, reducing the distal embolization of microfragments of the atherosclerotic plaque. Although effective in reducing embolic phenomena, this method causes a temporary interruption in cerebral blood flow, which is not always well tolerated by patients (especially in the presence of contralateral carotid occlusion or anomalies in the circle of Willis). The good results initially reported by Theron et al could not be universally reproduced, and several cases of cerebral ischemia resulting from the use of this system were reported ${ }^{19,21}$. In addition, operational technical difficulties made it less and less used.

In 1996, Kachel ${ }^{22}$ who used a 9F balloon reported a reverse blood flow system through the external carotid artery based on occlusion of the common carotid artery close to its bifurcation. Despite being simple and of easy applicability, later studies showed that this system was neither safe

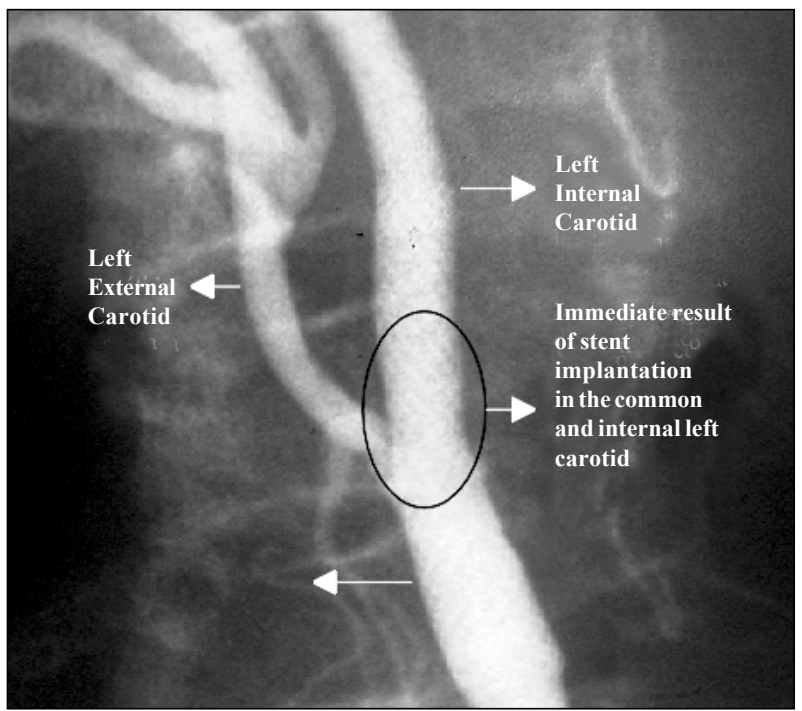

Picture 2 - Endoprosthesis (stent) implantation of the self-expanding type (Wallstent) extending from the left common carotid artery to the left internal carotid artery. The origin of the left external carotid artery was not obstructed, maintaining a good flow. According to the on-line digital angiography, the degree of residual lesion was $<10 \%$. 


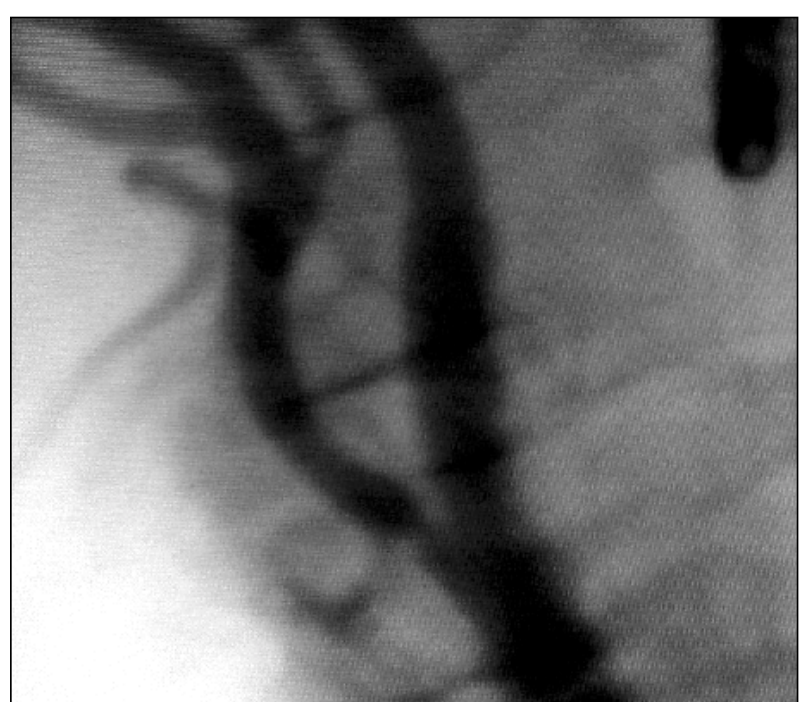

Picture 3 - After 18 months, the patient underwent a new carotid angiographic study, which showed maintenance of the immediate result with residual lesion $<10 \%$. After the end of the process of endothelialization of the prosthesis, patency of the left external carotid artery was observed. A $50 \%$ stenosis in the left external carotid artery ostium was noted on quantitative angiography, but this finding did not result in clinical manifestations.

nor efficient in preventing distal microembolization, especially in the presence of cerebral collateral circulation, which currently makes it rarely used ${ }^{23}$.

In 1999, carotid filters appeared and provided the following advantages: effectiveness in preventing microembolization (fragments of up to 100 micrometers), no interruption of the cerebral blood flow during its use, and easy manipulation ${ }^{24}$. Among the deficiencies of the device, we can cite the following: the filters are rigid, making their passage into more significant stenoses difficult; the difficulty in adjusting the size of the filters to the carotid diameter in each patient; and, mainly, their still extremely elevated costs to allow their inclusion in our current practice ${ }^{25}$.

It is worth noting that at the time these data were gathered, these devices were not available for use at the hospitals where these patients were treated, and that, up to March 2001, no model had been approved for use in clinical practice by the agencies that regulate medical practice in the USA (Federal Drug Association - FDA) and in Brazil (Ministry of Health).

The most appropriate patients for carotid percutaneous interventions are as follows: those with isolated ca- rotid disease and severe flow obstruction close to the angle of mandible, inaccessible to surgery; those with radical dissection of the neck followed by radiation therapy (the cases of cervical neoplasias, for example); those with restenosis after carotid endarterectomy; and those with fibromuscular dysplasia ${ }^{12,21}$.

In our group of patients, the $98.9 \%$ rate of success revealed the efficiency of the percutaneous treatment, and, if the patients are analyzed according to the presence or absence of symptoms, the combined rate of (major/minor) ischemic cerebral stroke was $5.4 \%$ for symptomatic patients and $0 \%$ for asymptomatic patients. In the group of asymptomatic patients, the estimated rate of complication was considerably low and inferior to that defined for carotid endarterectomy according to the American Heart Association ${ }^{12}$.

These data become more relevant when we consider that of the 86 patients analyzed in this study, $43(50 \%)$ were in the subgroup classified as high risk for interventions, because they were old, had contralateral carotid occlusion (5.8\%), had already had a previous cerebral stroke (5.8\%), had already been revascularized (4.6\%), or because they had the so-called "hostile neck", ie, they had had cervical neoplasia or had undergone previous radiation therapy in the cervical region, or both (3.5\%).

Currently, the Stent versus Carotid Endarterectomy (CREST) study is being carried out by the National Institutes of Health under the leadership of Dr. Hobson. In this study, 2,500 patients will be randomized. The results of the CREST study will define whether one technique is superior to the other.

Carotid stent implantation already plays a significant role in the treatment of carotid atherosclerotic disease. It is undeniable that the $98.8 \%$ rate of success and the $4.2 \%$ rate of cerebral stroke/death in our study show the efficiency and safety of this type of procedure. We also know that the improvement in the materials used (introducers, catheters, guidewires, endoprostheses, etc.) and the appearance of new devices have significantly contributed to improve the results of percutaneous implantation of carotid endoprosthesis.

In some studies, the devices used for cerebral protection have had the ability to reduce the indices of neurological complications ${ }^{26}$. This has increased interest in the scientific community, generating more clinical trials that will shortly define the actual role played by these devices in carotid endoprosthesis implantation.

\section{References}

1. Dorros G. Carotid arterial obliterative disease; should endovascular revascularization (stent supported angioplasty) today supplant carotid endarterectomy. J Intervent Cardiol 1996; 9: 193-6.

2. Debakey MH. Carotid endarterectomy revisited. J Endovasc Surg 1996; 3: 4.

3. Englewood CO. Patient outcomes research teams study groups. Stroke Clinical Updates. Nat Stroke Assoc 1994; 5: 9-12.

4. Americam Heart Association. Heart and Stroke Facts Statistical Supplement. New York: American Heart Association, 1994: 12.
5. Andrade LAF, Tilbery CP, Pimentel PCA, et al. Acidente Vascular Cerebral In: Knobel E. Condutas no Paciente Grave. São Paulo: Atheneu, 1999: 630-47.

6. Diethich EB. Cerebrovascular disease therapy; the past, the present, and the future. J Endovasc Surg 1996; 3: 7-9.

7. Joye DJ. Carotid Up to Date. Fellow Courses Transcatheter Cardiovascular Treatment, 2001.

8. Mathias K. Ein neuartiges Katheter-System zur perkutanen transluminalen Angioplastie von karotisstenosen. Fortschr Med 1977; 95: 1007-11. 
9. Mathias K, Mittermayer C, Ensinger H, et al. Perkutane katheterdilatation von karotisstenosen. Rofo 1980; 133: 258-61.

10. Joye DJ. Carodit Up to Date. Fellow Courses Transcatheter Cardiovascular Treatment, 2000

11. Brott T, Adams HP, Olinger CP, et al. Measurement of acute cerebral infarction: a clinical examination Scale. Stroke 1989; 20: 864-70.

12. Moore WS, Barnett HJM, Beebe HG, et al. Guidelines for carotid endarterectomy: a multidisciplinary consensus statement from the ad hoc committee. American Heart Association. Stroke 1995; 26: 188-200.

13. Zarins CK. Carotid endarterectomy:the gold standart. J Endovasc Surg 1996; 3 : $10-15$.

14. Lusby RJ, Wylie EJ. Complications of carotid endarterectomy. Surg Clin Nort Am 1983; 63: 1293-301.

15. Farrell B, Fraser A, Sandercock P, et al. European carotid surgery trial (ECST). Lancet 1998; 351: 1379-86.

16. Bernett H. North American Symptomatic Carotid Endarterectomy Trial Colaborators (NASCET). Beneficial effect of carotid endarterectomy in symptomatic patients with higth-grade carotid stenosis. N Engl J Med 1991; 325: 453-5.

17. White CJ. Asymptomatic Carotid Atherosclerosis Study Group (ACAS). Endarterectomy for asymptomatic carotid artery stenosis. JAMA 1995; 273: 1421-8.
18. Brow MM. For the Carotid and vertebral artery transluminal angioplasty study investigators (CAVATAS). Results of the carotid and vertebral artery angioplasty study. Br J Surg 1999; 86; 710-11.

19. Whole M, Roubin G, et al. Global experience in cervical carotid artery stent placement. Cathet Cardiovasc Interven 2000; 50: 160-7.

20. Théron JG, Payelle GG, Coskun O, etal. Carotid artery stenosis: Treatment with protected balloon angioplasty and stent placement. Radiology 1996; 201: 627-36.

21. Henry M, Amor M, Masson I, et al. Angioplasty and stenting of the extracranial carotid arteries. J Endovasc Surg 1998; 6: 293-304.

22. Kachel R. Results of balloon angioplasty in carotid arteries. J Endovasc Surg 1996; 3: 22-30

23. Théron JG. Cerebral protection during carotid angioplasty. J Endovasc Surg 1996; 3: 484-5.

24. Iyer SS. Treatament of extracranial carotid disease: Stents reign supreme. Transcatheter Cardiovascular Treatment. Washington DC, USA, 2000

25. Diethrich EB. Indications for carotid stenting; a preview of the potential derived from early clinical experience. J Endovasc Surg 2000; 3: 132-9.

26. Roubin GS. Carotid artery intervention free of emboli (CAFE-USA). American Heart Association Scientific Session. Washington DC, USA, 2001. 